DOI 10.32370/IA_2019_01_16

\title{
The Role of the Coloristic Solution in the Modern Art as a Constituent Part of the Tapestry
}

\author{
Borisyuk Z. D. \\ Senior Lecturer of the Department of Theory and Methodology of Decorative \\ Arts, graphic arts and graphic faculty of the State institution "South Ukrainian \\ National Pedagogical University named after K. D. Ushinsky"
}

Bogaychuk L. R.

\author{
Senior Lecturer of the Department of Theory and Methodology of Decorative \\ Arts, graphic arts and graphic faculty of the State institution "South Ukrainian \\ National Pedagogical University named after K. D. Ushinsky"
}

\begin{abstract}
The article is devoted to the role of the coloristic solution in contemporary art and the problem of the coloristic solution of the tapestry composition. It is indicated that the need for a deeper and more comprehensive study of the art of tapestry is due to the fact that the modern art of the 21 st century is characterized by the search for a new coloristic composition solution, which is also associated with a certain shift in the boundaries between its individual types and genres. Poorly lit parts of the problem are identified. Since a modern tapestry is one of the most "contact кол coloristic" genres of decorative art and its language is emotional on the basis of, above all, a coloristic solution, there is a need to identify and clarify the principles for constructing a decorative and coloristic composition of the tapestry.

Based on the goal of the research on creating an overall picture of the formation and development of a coloristic solution of tapestry composition in the context of modern art trends, the need to identify and substantiate the role of a coloristic solution as an important part of the composition in a modern tapestry is noted. The conclusions emphasize the role of the color solution when creating the tapestry. It is substantiated that the color sketch of the tapestry composition allows for a mobile search for a different, tonal, rhythmic and coloristic image solution, in accordance with a clearly defined compositional and emotional-imaginative task, since color contributes to emotional impact. Such a rather complicated process and multifaceted work on the composition of the tapestry allows students to create interesting, imaginative and emotional tapestries as the final stage in the work on the educational theme "Decorative color composition of the tapestry".
\end{abstract}

Key words: decorative and applied art, color, color solution, composition, tapestry.

Introduction. The need for a deeper and more comprehensive study of the art of tapestry is due to the fact that modern art of the 21 st century is characterized by the search for a new coloristic composition solution, which is also associated with a certain displacement of the boundaries between its particular types and genres. 
In modern conditions, the application of new technologies in the artistic activity of students and the expansion of the possibility of mass replication of works of applied art, the importance of handicraft art is increasing, and in the artistic design the legacy of historical styles. In accordance with such trends in the development of the tapestry, there is a need for a conceptual revision of the content of the training course "Tapestry and the basics of the decorative color composition."

The degree of elaboration of the problem. From the history of the problem it appears that attempts were made to create a theoretical basis for studying the tapestry, which were reflected in the works and scientific works of E. Antonovich, R. Zakharchuk-Chugai, M. Stankovich [1], M. Agranovskaya, N. Anurova, S. Beskinskaya, N. Voronova, V. Elizarova, T. Zinovievon, R. Koval, N. Monahova, N. Stephenyan, T. Strizhenova, N. Uvarova, G. Ookilova, V. Viduka, L. Zhogol, S. Kalniete, M. Nekrasova, O. Negnevitskaya and others.

Various issues of stylistics, composition and innovations in the works of artists engaged in tapestry were identified in the works of V. Savidko, I. Ryumin, L. Kramarenko. At the beginning of the XXI century the studies of the tapestry development was reflected in the articles, exhibition catalogs and books of such authors as L. Kramarenko, N. Tsvetkova, N. Anikina, A. Vasilchenko, T. Anfilova, M. Zarif, L. Kalinushkina, T. Leshchenko [3], Yu. Mamontov, M. Novikova, O. Oreshko, M. Putilovskaya, K. Sokolsky, V. Savitsko [4], T. Strizhenova [5] and others.

Various aspects of the connection between folk art and contemporary tapestry are revealed in the works of I. Boguslavskaya, A. Chekalova, T. Razin and other authors. Contemporary artists who are engaged in the art of tapestry E. Tkachenko, N. Muradova, T. Sazhin, S. Gavin, F. Lvovsky, N. Tsvetkova. A. Kozorez, O. Levadnaya, L. Kramar, O. Oreshko, E. Odintsova and others, reveal the specific points of the coloristic decision of the tapestry composition.

Insufficiently lit parts of the problem. As a modern tapestry is one of the most "contact кол coloristic" genres of decorative art and its language is emotional based, above all, on a coloristic solution, there is a need to identify and clarify the principles for constructing a decorative and coloristic composition of the tapestry. 
The purpose of the study is to create an overall picture of the formation and development of a coloristic solution of tapestry composition in the context of modern art trends. Identify and justify the role of the color palette as an important part of the composition in a modern tapestry.

The main content (research methodology). The study of the color palette of the tapestry composition required the use of an integrated approach: a comparative-historical method (the trends in artistic creativity at the turn of the 20th and 21st centuries are revealed); method of art criticism (the stylistic features of the traditional coloristic solution of the composition and its features in the modern tapestry are revealed).

On the basis of the theoretical and methodological foundations of the study, it was revealed that the history of the development of the tapestry color solution is a history of development, first of all, of its connection with space. The compositional color palette of the modern tapestry is based on the fact that the canvas moves away from the wall, a threedimensional composition is created, and various hand weaving technologies are combined. Artists tend to strive to show their authorship in the art of tapestry, to show creative individuality through finding the coloristic composition of the tapestry.

The main content (Discussion). Currently, tapestries are called not only woven carpets, but also many other products woven using the technique of cross-weaving threads. In the definition, tapestry (tapestry) is a hand-woven carpet pattern. Characteristic of the tapestry is the following: the ribbed surface of the front side, created by the warp threads, and the uneven surface of the reverse side, formed by the seams and weft threads. Tapestry - this is such a piece thing, which has its own special character. It is based on a sturdy pattern, rigorous calculation of all decorative effects, and then - a long, patient embodiment in the material.

From the history it follows that each generation, inheriting the technical skills and techniques of decoration, left its mark on the collective creativity of the people and reflected its view of the world. At the same time, the themes of the tapestry - paintings are diverse: decorative flowers, still lifes, animals, episodes of historical events, classical scenes, cathedrals and churches, landscapes. The traditional and updated tapestry, above all, is a fashionable and relevant element of interior design, successfully complementing the color space and there will always be a place for it. 
During the studies, each student can find their own individual style, create unique tapestries, compositionally - coloristically interesting and professionally made, if the necessary learning conditions are created.

From the study of M. Merenyasheva, V. Mitina, it is possible to single out the position that a traditional tapestry as one of the types of decorative and applied art, a wall lint-free carpet with a plot or ornamental composition, manually weaved by a cross-weave of colored silk or woolen threads as one of the plastic art forms, it is distinguished by its inherent expressive qualities in the creation of artistic images, in solving their composition. Each work is an artistic experiment, an attempt to develop new principles for the organization of its plastics. But in design, the possibilities of the tapestry are far from being exhausted; their comprehension must "go hand in hand" with practice.

According to M. Merenyasheva, V. Mitina, the history of the tapestry is based on the notion that the classical tapestry was determined by the size and configuration of the architectural space. It was a painting made by weaving craft and filling the flatness of the wall. The composition of the tapestry, the color palette and the character of the stylization of the drawing were determined by the painting of its time. Such an influence of space can be characterized as a plot-compositional one. Tapestry here was used only as a decorative spot or composite accent. Synthesis elements were weak or absent. The tapestry had traditional rectangle shapes and small sizes. The overall emotional impact of the tapestry - the decorative plane - depended on the correct scale of the composition and its orientation in space. Later, the enhancement of the emotional impact of the tapestry began to be achieved by departing from the classical rectangle in its composition and by introducing an active silhouette solution - a circle, a circle in combination with a rectangle, a few bands. And also by plastic development of the flatness itself [7].

A distinctive feature of the modern tapestry is the aesthetically active role of the textile material itself, the variety of weaving techniques. The introduction of new, unusual for the old tapestry materials such as sisal and jute, cords, sheep fleece, metal yarns, synthetic yarn, flax and hemp, and others, allows you to achieve a much greater variety and texture expressiveness of works. The variety of materials for weaving is accompanied by the use of modern techniques, such as appliqué and embroidery. In the modern tapestry, two ways of 
transmitting figurative content were developed. The first is to use for the disclosure of the idea of a very specific subject-thematic pictorial "language". The second is to use the "language" of a somewhat abstract, complicated form, the meaning of which is not immediately revealed. In the second case, the artist involves the viewer in the process of cocreation, makes you think, open the idea of the work yourself. The tapestry language is emotional, the modern tapestry is one of the most "contact" genres of decorative art. The author finds the emotionality in the principles of the construction of a decorative composition, in the selection of color combinations, in the uniqueness of this or that technical innovation. The shape, color combinations, connection of unusual moments in shape and surface - all this is the purpose of the design and designs the vision of the image of the tapestry in space [7].

The study of the tapestry of L. B. Semizorova highlights the position that the assertion by the decorative art of its equality with other types of artistic creativity led to the metamorphosis of the tapestry: from classical planar through textured and embossed to independent textile structures, the creation of which is impossible without the simultaneous use of weaving techniques, painting, sculptures. A new artistic phenomenon, traditionally called the "tapestry", is a complex synthetic alloy that incorporates the features of several genres at once and appears in countless ways: from "fabric painting" to "textile" plastics. If a tapestry, like a fresco, was an integral part of architecture, that is, it was a work of monumental art, then over time it becomes a work of easel, more mobile and diverse in both form and technique [8].

In hand weaving there was an interest in the texture, texture and plastic effects of the fabric surface. In turn, this required the artist to master the entire rich heritage of tapestry and carpet weaving of past years and eras. It has become important to combine color and texture, brightness and dimness, smoothness and roughness, density and delicacy in a tapestry in a single harmony. Masters experimented with the manufacture of new dyes. Used for this natural materials: flowers, leaves, roots, moss, bark, all this greatly expanded the scope of the creative possibilities of the artist. The artists' experiments followed one after the other: color and texture discoveries, structural and plastic techniques, complicated rhythmic interpretation of color, shape and volume. The search for new structures and textures led to the use of synthetic materials, to sisal, to cords, leather, sheep fleece, horsehair, metallic threads, which were introduced into the fabric along with such "eternal" weaving materials as wool, linen, hemp, silk. The canvas is stretched on wooden, plastic or metal structures. The tapestry does 
not just belong to the wall, it "soars" in the air, it exists as a three-dimensional composition. Tapestry crossed the last threshold of conditionality - broke away from the wall. The weaving technology itself has been modernized. Along with the classical methods (trellis), hiding the basis, the master introduces a looser weave system, showing both the basis (making through cuts) and the fabric structure itself, alternating coarse stitches with small ones, openwork with dense fabric, achieving constant contrasts [8 ].

In the conclusions of L. Semizorov, it is possible to single out that the tapestry in the 20th century. rightfully called "active plastic". The experience gained by domestic artists of the second half of the 20th century makes us appreciate the specifics of hand weaving art in a different way. She connects the stages of the formation of hand weaving with the fact that the tapestry was subject to the laws of impact not only of weaving and painting, but also of plastics, and thus it was included in the new system of plastic thinking, which was based on the new perception of space, time and the internal structure of the subject. The introduction of the tapestry into the interior ensemble caused major changes in the development of the genre itself, led to the emergence of new principles of compositional solution, expanded the use of materials and techniques, and led to the strengthening of monumental beginnings. The tapestry has become a synthetic art form, there has been a blurring of the boundaries of painting, sculpture, architecture [8].

It is possible to draw attention to the performance of A. Wexler, that a decorative color composition is one of the types of professional artistic activity in the field of decorative and applied art, the final product of which is an artistic work made in a mixed technique, taking into account the conditions and tasks of a particular artistic and plastic language - the language of decorative art. The language of the decorative color composition enables each student to find his own artistic and plastic solution in the work on the educational production. As a result of this work done, the training statement made by the student should become an independent author's decorative artwork in which the system of relations between space and plane, symmetry and rhythm, statics and dynamics harmoniously built; relations of light and shadow, interrelations of colors, plans of the visual space - interrelation of components of a pictorial image, real content and conditionally decorative image [9]. 
In general, in the context of our research, we single out the most important thing: in art, compositional mastery is the basis of the creative process, in which the unity and integrity of the form of a work of art are determined by its content.

Since when making tapestries it is necessary to take into account a number of laws of composition, we draw attention to the fact that composition is an essay, a combination of elements into a single whole according to the laws of harmony. Elements, objects, units of composition can be very different, but all of them are subject to "binding", layout. The word "composition" comes from the Latin composition - to compose, bind. In the modern sense, composition is the construction of a work of art, due to the specifics of the type of art, the content, the purpose of the work, and the plan of the master.

In the work on the tapestry it is necessary to take into account a number of laws of composition. The basic laws of composition should be called the following: the law of integrity, contrasts, balance, the law of subordination of all means of composition to the ideological plan, and others. To clearly and fully express your intention in the work, you need to know the law of integrity - the basic law of composition. The main feature of the law of integrity is the indivisibility of composition, i.e. communication and mutual consistency of all elements of the composition. On the basis of the constructive idea, the center of attention stands out, subordinating the secondary to itself. All elements of the composition should work on the general idea. The law of contrasts is one of the basic laws of composition. The term "contrast" means a sharp difference, the opposite of the sides. The main contrasts in art are hue (light) and color natural contrasts. On their basis, other types of contrasts arise and act contrasts of lines, shapes, sizes, characters, states. As well as contrasts associated with ideas (contrasts of ideas, positions), contrasts in plot construction (contrasts in finding a constructive idea), etc. Any properly constructed composition is balanced. Equilibrium is the placement of the elements of the composition, in which each object is in a stable position. His location is not in doubt and desire to move him on the visual plane. Equilibrium can be of two types: a) static equilibrium occurs when the symmetrical arrangement of the figures on a plane relative to the vertical and horizontal axes of the format of a composition of a symmetrical shape; ) dynamic equilibrium occurs when an asymmetric arrangement of figures on a plane, i.e. when they shift to the right, left, up, down. When arranging forms on a plane, 
the scale and proportions of the displayed values play a large role. The expressiveness of the composition depends on their correct use.

The compositional and coloristic decision of the tapestry composition is associated with the notion that color is a powerful source of influence on the human psyche and his emotional state. An important step in the work is the compilation of a range of tapestry. Color is understood as the richness and character of the shades introduced into the work and its individual parts, as the prevailing selection of tones in the work. The presence of pure contrasting colors in the gamut ensures maximum color contrast and sonorous sounding of other shades [10].

In the classes of students of the Faculty of Art and Graphics to implement a coloristic composition of a contemporary tapestry, we have developed a plan that consists of the following stages: introductory lesson; individual tapestry composition on an architectural theme; pointless gobelin composition; tapestry in the design of textile products; collective tapestry; author tapestry;

Training methods, V. Radkevich, which may be used for the implementation of: eplanatory - illustrative: intonational selection by the teacher of logically important moments; maintenance of the generalized conclusions by the teacher, using concrete examples; demonstration of reproductions, photographic materials, finished works of students, visual aids to illustrate the new material; reproductive: the organization of students mastering the standard methods of action using the situation of choice; prompting students, encouraging them to be creative, to be creative in studying new material; research: independent production of the product from the choice of the theme to the design of the finished tapestry; project activities of students.

In the process of learning, the following types of studies are provided: a typical lesson (combining explanation and practical exercise), a guided tour, a practical exercise under the guidance of a teacher to consolidate certain skills, independent production of a specific product, a learning game. In the course of training, the following types of control were provided: input, which is held before the start of work and is intended to identify knowledge and skills in weaving; current, conducted during the training session and reinforcing knowledge on this topic. It allows students to learn the sequence of technological operations; 
milestone, which is held after the completion of the study of each section, the final, held after the completion of the curriculum. The result of the knowledge and skills gained is of great importance the collective analysis of creative works, as well as participation in competitions and exhibitions.

Conclusions. On the basis of the analyzed material it is possible to make certain generalizations and conclusions.

Adoption of equality with other types of artistic creativity by the decorative art led to a metamorphosis of the traditional tapestry: from classical planar - through textured and embossed - to independent textile designs, the creation of which is impossible without the simultaneous use of weaving techniques, painting, sculpture, and most importantly - finding a certain coloristic solution.

In the modern tapestry there is an active plastic and planar composition of the tapestry, ornamental stylization, the use of three-dimensional pile weaving of Oriental carpet and the author's vision of the artist, his own image in the composition.

The tapestry is characterized by coloristic and textured revelations, structural and plastic tumors, a complicated rhythmic interpretation of color, shape and volume in space.

The color sketch of the tapestry composition allows you to conduct a mobile search for a different, tonal, rhythmic and coloristic image solution, in accordance with a clearly defined compositional and emotional-imaginative task, as the color contributes to emotional impact.

The work directly on the tapestry's picturesqueness makes it possible to find the final composition of the "sheet", clarify the forms, silhouettes and proportions of objects and elements, reveal nuanced coloristic and tonal relationships, determine the diverse nature of textures and the figurative informational content of the tapestry.

Prospects for further research. The rather complex process and multidimensional work on the coloristic solution of the tapestry composition allows students to create interesting, imaginative and emotional tapestries as the final stage in the work on the educational theme "Decorative color composition of the tapestry", which requires further study. 


\section{References}

1. Antonovich, E.A., Zakharchuk-Chugai, R.V., Stankovich, M.E. (2010) Decorative arts, Lviv: Svit. - 272 p.

2. Problems of composition: Sat. scientific Proceedings / Edited by V.Vanslova (2000), M .: Image. Art. - 292 p.

3. Leshchenko, T.A. (2005) Non-woven tapestry, Rostov n / D.:Phoenix. - 144 p.

4. Savitskaya, V. (1995) Transformations of the tapestry, M .: Galart. - 87 p.

5. Strizhenova, T. (1975) Tapestry and the image, M., DI SRSR. - №9. - P. 31-34.

6. Niukute, Yu. (1985) Aesthetic Problems of Contemporary Decorative and Applied Art: Abstract ... Cand. art history, M. - 29 p.

7. Merenyasheva, M. A., Mitina, V.O. (2014) Harmonious image in the tapestry. Entry into space // Modern scientific research and innovation. № 4. Part 2 [Electronic resource]. URL: http://web.snauka.ru/issues/2014/04/33721 (appeal date: 09/23/2018).

8. Semizorova, L. B. (2011) Features of the development of the national tapestry art: Specialty HAC: 17.00.04. - Fine and decorative arts and architecture, Ekaterinburg, - 28 p.

9. Veksler, A. (2013) Decorative color composition. Study Guide // Letters to the Issue. The Emissia. Offline Letters: electronic scientific journal. Methodical application, MET 007. Cpb. - 64 p.

10. Tapestry. Great Soviet Encyclopedia. - Vol. 6. - 456 s. Tapestry [Electronic resource]. URL: https://readtiger.com/wkp/ru/ (appeal date 12/11/2017).

11. Radkevich, V. O. (2000) Concepts of professional art // Professional and Technical Review. - №2. - P. 43-47. 